\title{
Werner Paravicini, Die Wahrheit der Historiker
}

München: Oldenbourg, 2010, 94 p., 29,80€

Thomas Lienhard

\section{OpenEdition}

\section{Journals}

Édition électronique

URL : http://journals.openedition.org/ifha/7727

DOI : $10.4000 /$ ifha. 7727

ISSN : 2198-8943

Éditeur

IFRA - Institut franco-allemand (sciences historiques et sociales)

Référence électronique

Thomas Lienhard, "Werner Paravicini, Die Wahrheit der Historiker », Revue de l'IFHA [En ligne], Date de recension, mis en ligne le 13 décembre 2013, consulté le 22 septembre 2020. URL : http:// journals.openedition.org/ifha/7727 ; DOI : https://doi.org/10.4000/ifha.7727

Ce document a été généré automatiquement le 22 septembre 2020

(CIFHA 


\section{Werner Paravicini, Die Wahrheit der Historiker}

München: Oldenbourg, 2010, 94 p., 29,80€

Thomas Lienhard

Dans ce bref ouvrage, l'auteur entend s'opposer à des postures critiques remettant en cause la vérité que propose l'historien. Il commence donc logiquement par dresser un panorama de ces questions radicales envers la véracité du discours scientifique sur le passé : si l'histoire est une science cohérente, pourquoi n'a-t-elle pas encore fait le tour de son objet alors que les sources concernant le Moyen Âge, par exemple, sont généralement connues depuis longtemps? Ces sources sont-elles autre chose qu'une pure création littéraire par leurs auteurs? A-t-il vraiment existé des faits, ou ceux-ci ne sont-ils qu'une construction arbitraire des historiens? Et à supposer qu'ils soient définissables, chaque historien ne les détourne-t-il pas indument lorsqu'il les recompose à son gré? Si l'on suit de telles remises en cause, le projet d'une reconstruction scientifique du passé est vain. Ce sont ces croyances, selon W. Paravicini, qui expliqueraient la prolifération des études sur la mémoire plutôt que sur le passé qui a servi de départ à cette activité mémorielle (et l'auteur se fend de quelques piques envers l'historiographie de la memoria, soulignant avec ironie le fait qu'elle soit particulièrement développée à propos des contextes pour lesquels les sources sont rares). L'auteur met cette évolution hypercritique en relation avec l'actuelle crise des postes dans université allemande, et cette analyse sociologique est peut-être la partie la plus instructive de l'ouvrage pour le lecteur français : puisqu'il est plus rapide de produire un nouveau discours sur l'histoire que de le fonder sources à l'appui, les jeunes chercheurs d'outre-Rhin, pressés par des financement de plus en plus brefs, seraient naturellement portés à épouser les critiques les plus radicales envers la science de leurs aînés, ou à adhérer à l'un des turns qui ont marqué les sciences humaines récemment, plutôt qu'à labourer péniblement des corpus de sources avec la méthodologie de leurs aînés.

Face à ces critiques, l'auteur commence par rappeler qu'elles ne sont guère innovantes puisque selon lui, elles remontent sinon à Pierre Bayle, du moins à Kant, Schopenhauer 
et Nietzsche. Cette ancienneté ne leur sert pas de garantie, et W. Paravicini leur oppose la résistance des faits historiques: si l'historien ne peut prétendre à l'entière vérité, on peut en revanche qualifier d'entièrement faux certains discours sur le passé. Par suite, une forme de validation scientifique du discours historique est possible, et pour les questions consistant à déterminer où, quand et comment s'est produit tel phénomène (W. Paravicini ajoute: "et pourquoi", affirmation envers laquelle on sera plus prudent), l'historien conserve le monopole de l'enquête. L'ouvrage ne se fixe pas pour objectif la définition des étapes suivantes dans le travail des historiens, mais uniquement le rappel d'une pierre de touche pour les jeunes chercheurs, auxquels W. Paravicini destine explicitement son ouvrage: il est possible de déterminer des vérités historiques.

Ni la question ni les réponses ne sont neuves, et l'auteur le reconnaît explicitement, même si on aurait pu attendre, de la part de ce bon connaisseur de l'université française, quelques références aux débats de même nature qui ont animé celle-ci depuis quelque quarante ans. Par ailleurs, W. Paravicini assume parfois une posture délibérément réactionnaire, par exemple lorsqu'il affirme que les fresques historiques sont de retour dans les évolutions de l'art récent (je n'en suis pas convaincu), ou que le minutieux travail d'édition est plus précieux aux historiens que ne le sont les modèles ou les théories philosophiques (l'oxygène aussi, mais cela ne suffit pas pour faire de ce gaz la quintessence du travail historien). Ce qui demeure perturbant au terme de cet ouvrage, c'est qu'un intellectuel de la trempe de W. Paravicini ait jugé nécessaire, compte tenu des évolutions qu'il percevait dans l'historiographie allemande, de consacrer cet ouvrage certes bref à une question apparemment triviale. Signal inquiétant sur l'histoire en Allemagne?

INDEX

Thèmes : Historiographie/Methodologie

Index chronologique : Epochenübergreifend

\section{AUTEUR}

THOMAS LIENHARD

Paris I, LAMOP 